\title{
Pathomorphological, Haemato-biochemical and Diagnostic Imaging Studies in Canine Pyometra
}

\author{
K. Haripriya Achary ${ }^{1}$, P.K. Rath ${ }^{1}$, S.K. Panda ${ }^{1}$, B.P. Mishra ${ }^{2}$, Biswadeep Jena ${ }^{3}$, R. Mishra ${ }^{4}$
}

10.18805/IJAR.B-4806

\begin{abstract}
Background: Pyometra is the most common genital affections observed in bitches around the globe in-spite of advancement of disease diagnosis and treatment. Paucity of available literature regarding pyometra in canines in Odisha prompted to undertake an in-depth analysis on determinants linked to epidemiology, haemato-biochemical, clinicopathological and diagnostic imaging in pyometra bitches.

Methods: During the period 2019-20, a total of 148 bitches were screened for canine pyometra in and around Bhubaneswar, Odisha on the basis of clinical signs, haematology and diagnostic imaging. Uterus was collected after ovario-hysterectomy and processed for histopathology through routine haematoxylin and eosin staining.

Result: The overall incidence of pyometra was $15.54 \%$ with $4 \%$ mortality rate. Present study recorded a significant higher occurrence of pyometra in older bitches (>7 year, $78.26 \%$ ), smaller breeds like Spitz $(47.82 \%)$, nulliparous bitches $(60.86 \%)$ and dogs in dioestrus stage $(82.60 \%)$. Haematological examinations revealed anaemia with marked leucocytosis and neutrophilia. There was significant increase in AST, ALT, ALP and BUN concentrations in affected bitches. Enlarged uterus with hypo echoic tubular structures containing mostly echogenic fluids were constant findings through ultrasonography. Flabby uterine horns with thick and corrugated endometrial wall containing profuse mucopurulent exudates were seen during necropsy. Chronic inflammatory response leading to intense haemorrhages and hyperaemia were constant microscopic changes. The most common isolated pathogen in canine pyometra was Escherechia coli $(67.5 \%)$.
\end{abstract}

Key words: Canine pyometra, Dog, Haemato-biochemical, Mortality, Ultrasonography.

\section{INTRODUCTION}

Canine pyometra is considered as a common reproductive ailment in intact adult bitches during dioestrus stage and commonly manifested as accumulation of purulent exudates in the distended uterus with certain pathomorphological alterations and systemic signs (Rautela and Katiyar, 2019). Complex multifactorial aetiology of canine pyometra results in infertility, embryonal death as well as death of affected bitches if unattended. Progesterone surge along with reduced clearance of opportunistic bacterial pathogen may complicate the etiopathogenesis of pyometra in hormonally compromised uterus. Epidemiological risk factors like dioestrus stage, parity, breed as well as age (Ergene et al. 2019) play a pivotal role in the disease pathology. Early screening of pyometra through clinical signs, haematology, blood biochemistry as well as ultrasonography might be helpful in limiting the disease severity and death (Shah et al. 2017). The present study was aimed to study various epidemiological determinants and haemato-biochemical alterations along with pathomorphological changes in affected bitches which would educate the pet lovers as well as field veterinarians to refresh their knowledge on canine pyometra for early screening and assessing severity. The study would be useful in providing the solution for management of canine pyometra either through therapeutic regimen or by surgical removal of uterus through ovario-hysterectomy.
${ }^{1}$ Department of Veterinary Pathology, College of Veterinary Science and Animal Husbandry, Bhubaneswar-751 003, Odisha, India.

${ }^{2}$ Department of Livestock Products Technology, College of Veterinary Science and Animal Husbandry, Bhubaneswar-751 003, Odisha, India.

${ }^{3}$ Department of Surgery and Radiology, College of Veterinary Science and Animal Husbandry, Bhubaneswar-751 003, Odisha, India. ${ }^{4}$ Department of Veterinary Microbiology, College of Veterinary Science and Animal Husbandry, Bhubaneswar-751 003, Odisha, India.

Corresponding Author: P.K. Rath, Department of Veterinary Pathology, College of Veterinary Science and Animal Husbandry, Odisha University of Agriculture and Technology, Bhubaneswar751 003, Odisha, India. Email: drpkrath78@gmail.com

How to cite this article: Achary, K.H., Rath, P.K., Panda, S.K., Mishra, B.P., Jena, B. and Mishra, R. (2022). Pathomorphological, Haemato-biochemical and Diagnostic Imaging Studies in Canine Pyometra. Indian Journal of Animal Research. DOI: 10.18805/ IJAR.B-4806.

Submitted: 16-10-2021 Accepted: 24-12-2021 Online: 14-02-2022

\section{MATERIALS AND METHODS}

The dogs presented to the Teaching Veterinary Clinical Complex (TVCC) of the College of Veterinary Science and Animal Husbandry, Odisha University of Agriculture and Technology (OUAT), Bhubaneswar as well as Veterinary Polyclinic, Sahid Nagar, Bhubaneswar over a period of four months i.e., from December, 2019 to March, 2020 were screened for pyometra on the basis of history, clinical 
examination, abdominal palpation, blood examination, ultrasonography and radiography.

Blood was collected from 33 bitches (Control-10, Affected-23) for routine haemato-biochemical examination. Uterus $(n=8)$ removed during ovario-hysterectomy were observed for gross morphological alterations while representative tissue preserved in $10 \%$ formalin processed for routine haematoxylin and eosin staining to observe microscopic lesions. Uterine exudates $(n=8)$ collected in sterile container aseptically subjected for bacteriological culture and gram staining for identifying the bacterial pathogen.

The recorded data was statistically analysed by using SAS software (Local, W32_7pro) through student's t-test and Chi-square test to find the significance of association among the various risk factors in occurrence of canine pyometra. The value of $p \leq 0.05$ was accepted as statistically significant.

\section{RESULTS AND DISCUSSION Epidemiological risk factors}

A total of 148 numbers of dogs belonging to different breeds with some sorts of gynaecological complains were presented for seeking veterinary care to the TVCC of the college as well as Polyclinic, Sahid Nagar, Bhubaneswar, from which only 23 were screened for Canine Pyometra showing overall incidences of $15.54 \%$. The present study revealed the death of only one bitch due to pyometra with overall mortality of approximately $4 \%$. Prevalence as well as mortality pattern in pyometra affected bitches as observed in the present study was in accordance with Jitpean et al. (2014) and Antonov et al. (2015).

The present study reported higher occurrence of pyometra among the older dogs i.e., > 7-year age (78.26\%) followed by $4-7$ years age group $(17.39 \%)$ and least occurrence in 1-3 years age group (4.34\%). Higher incidences in adult bitches of more than 7 years of age might be attributed to other concurrent co-morbid conditions thus amplifying the severity of clinical conditions as well as incidences of the disease (Wheaton et al. 1987; Robaj et al. 2018). Breed wise occurrence of pyometra in present research study revealed higher affections among smaller breeds (Spitz-47.82\%) as compared to larger breeds of dogs (Lbrador-26.08\%, Alsatian-8.69\%, German Sepherd$4.34 \%$ ). Significantly increased incidences of pyometra in Spitz breed might be associated with higher genetic predisposition, frequent incidences of hormonal disorders during dioestrus periods and / or increased populations as one of the preferred toy dog breeds for the animal owners (Simon et al. 2011). Nulliparous bitches (60.86\%) more significantly suffered from pyometra than multiparous $(39.13 \%)$ animals. The immune-compromised state of multiparous bitches favour secondary bacterial infection and co-morbid conditions make them more susceptible for canine pyometra (Rautela and Katiyar, 2019). The present study revealed increased occurrence of open pyometra $(n=14$,
$60.86 \%$ ) followed by closed pyometra ( $n=9,39.13 \%$ ), which might be attributed to the progesterone surge that manipulates the uterine contraction and alters the protective functions of inflammatory cells in the uterine luminal environment and thereby causing settling of the infection in the uterus (Biswas et al. 2012). Most of the pyometra affected bitches were in dioestrus stage $(n=19,82.60 \%)$ which is in congruent with the findings of Simon et al. (2011) in bitches. Progesterone surge complicating with inhibitory response of the blood inflammatory cells particularly white blood cells (WBCs) inside the uterus facilitates the bacterial growth after each oestrus cycle thus further complicating and exacerbating endometrial pathology over the time (Sugiura et al. 2004). Season wise incidences revealed a significantly higher occurrence of pyometra in rainy season $(n=14$, $60.86 \%)$ followed by winter $(n=7,30.43 \%)$ and least occurrences in summer season $(n=2,8.69 \%)$ which related to the local geographical factors as opined previously by Antonov et al. (2015).

\section{Clinical signs}

Bitches suffered from pyometra showed elevated vital parameters with typical systemic clinical signs such as anorexia, frequent urination (polyuria), excess thirstiness (polydipsia), fever, vomition, pain on abdominal palpation, in-coordination, posterior leg weakness and diarrhoea. Dehydration was also evident in majority of bitches due to increased vaginal discharges from body. The mucus membrane became pale in most of the pyometric bitches. Clinical symptoms in canine pyometra as observed during the present research study were in accordance with Demirel et al. (2018) and Hagman (2018).

\section{Diagnostic imaging}

Diagnosis of pyometra can easily be done through diagnostic imaging like ultrasonography (USG) and radiography like X-ray imaging as suggested by Gasser et al. (2020). Diagnosis by ultrasonography revealed enlarged uterus with tortuous horns filled with hypoechoic and anechoic fluid with thickened uterine wall in most of the presented cases (Fig 1A). In some closed cervix pyometra cases, there was slow whirlpool like pattern of pus exudates inside the uterine lumen. Variations in thickening as well as contents of pus inside the lumen were clearly assessed through ultrasonography. Patency of cervix in open pyometra showing vaginal discharges along with thickened endometrial wall and absence of fluidic accumulations within the uterine lumen were characteristic finding in this study. The present findings were in accordance with the reports given by Kumar and Saxena (2018) in bitches. Ultrasonography is considered as an important indicator in pyometric bitches to direct the veterinarian to either go for surgery or therapeutic treatment for safe guarding the life of concerned animals (Sridevi et al. 2011). The radiographic study revealed the uterus as a fluid filled dense tubular structure inside the ventro-caudal aspect of abdomen when viewed in lateral recumbent position (Agrawal et al. 2015). 
Similarly, the radiographic evaluation showed the uterus as an enlarged tubular structure (Fig 1B) particularly in ventral and caudal abdomen clearly distinguished from the intestinal loops at the cranial and dorsal aspects in pyometric bitches with closed cervix. However, the uteri of the dogs with open cervix pyometra with clear and increased discharges from vagina were not well visualized through radiographic evaluation in the present study. In some cases, inability of the visualization of the uterus through radiographic examination may not rule out the possibility of existing pyometra. Enlargement of the uterine horns might lead to tubular structures of homogeneous opacity in the caudal and ventral aspects of the abdomen. In early enlargement, it may not be possible to differentiate the enlarged uterine horns from jejunum.

\section{Haemato-biochemical alterations}

Statistical analysis through student's t-test through SAS software concluded a significant $(P<0.05)$ difference between the apparently healthy control and pyometric bitches for various haematological parameters (Table 1). There was anaemia with resultant decreased packed cell volume (PCV) and total erythrocyte count (TEC) in affected dogs. Present study concluded a significant neutrophilia and relative lymphopenia in bitches affected with pyometra as compared to the control and apparently healthy nonpyometric bitches. Present findings were in accordance with Agrawal et al. (2015). Significant decreased $\mathrm{Hb}$, TEC and PCV in affected pyometra cases were suggestive of anaemia which could be related to suppression of bone marrow with reduced erythropoiesis in toxaemic conditions of closed cervix pyometra (Shah et al. 2017). Marked shift to left in pyometra affected bitches may be due to increased formation as well as early release of immature neutrophil to the blood circulation so as to combat or neutralize the proliferated bacterial loads in body (Mojzisova et al. 2000). Present findings of leucocytosis characterized by marked shift to left and lymphocytopenia in majority of pyometra affected cases are indicative of recovery from the disease and toxaemia (Kumar and Saxena, 2018).

The present research programme showed a significant increase in total protein, AST, ALT, ALP and BUN concentrations in pyometra affected bitches as compared to apparently healthy control non-pyometric bitches. Present findings are congruent with Sachan et al. (2019). There was a significant decrease in glucose and albumin concentrations in the affected dogs. (Table 2). Hypoalbuminaemia and relative hyperglobulinaemia could be due to the acute phase reaction and dehydration which is in accordance with Shah et al. (2017). Elevated serum enzymes like AST, ALP and ALT in pyometra
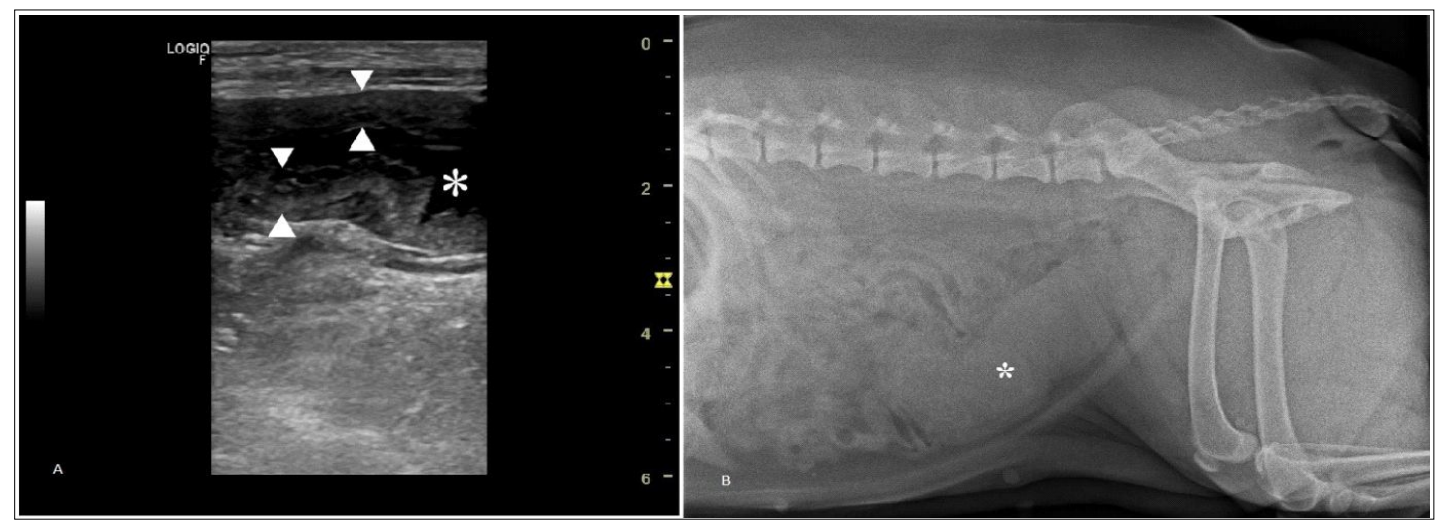

Fig 1: Diagnostic imaging of pyometra: (A) Enlarged, fluid filled uterine lumen with irregular thickened endometrial margins through USG. (B) Massive, tubular uterine distension through $\mathrm{X}$-ray radiography.

Table 1: Mean $\pm S E$ of haematological alterations in bitches affected with pyometra.

\begin{tabular}{|c|c|c|c|c|}
\hline Parameters & $\begin{array}{l}\text { Healthy control } \\
(n=10)\end{array}$ & $\begin{array}{l}\text { Pyometra cases } \\
\qquad(n=23)\end{array}$ & DF & P-value \\
\hline $\mathrm{Hb}(\mathrm{g} / \mathrm{dl})$ & $12.90 \pm 0.28^{a}$ & $9.10 \pm 0.19^{b}$ & 31 & $<0.0001$ \\
\hline TEC $\left(\times 10^{6} \mu \mathrm{l}\right)$ & $6.72 \pm 0.34^{\mathrm{a}}$ & $3.66 \pm 0.16^{b}$ & 31 & $<0.0001$ \\
\hline PCV (\%) & $39.10 \pm 0.82^{a}$ & $27.94 \pm 0.68^{\mathrm{b}}$ & 31 & $<0.0001$ \\
\hline TLC $\left(\times 10^{3} \mu \mathrm{l}\right)$ & $11.52 \pm 0.51^{\mathrm{a}}$ & $12.70 \pm 0.45^{a}$ & 31 & 0.0967 \\
\hline MCV (fl) & $59.72 \pm 3.53^{a}$ & $54.34 \pm 0.88^{a}$ & 31 & 0.1697 \\
\hline $\mathrm{MCH}(\mathrm{Pg})$ & $19.65 \pm 1.07^{a}$ & $19.29 \pm 0.47^{a}$ & 31 & 0.7230 \\
\hline $\mathrm{MCHC}(\%)$ & $33.06 \pm 0.72^{\mathrm{a}}$ & $32.42 \pm 0.40^{\mathrm{a}}$ & 31 & 0.4090 \\
\hline $\mathrm{N} \%$ & $65.70 \pm 1.78^{a}$ & $93.13 \pm 0.41^{\mathrm{b}}$ & 31 & $<0.0001$ \\
\hline L\% & $31.50 \pm 1.83^{a}$ & $6.30 \pm 0.33^{b}$ & 31 & $<0.0001$ \\
\hline $\mathrm{E} \%$ & $2.50 \pm 0.45^{\mathrm{a}}$ & $0.56 \pm 0.16$ & 31 & $<0.0019$ \\
\hline
\end{tabular}

${ }^{*}$ Mean \pm SE with different superscripts differ significantly $(P<0.05)$. 
cases are influenced by hepatocellular damage mostly intrahepatic cholestasis (Verstegen et al. 2008).

\section{Gross lesions}

Typical gross lesions in closed cervix pyometra revealed excessive distension of abdomen, inflamed vagina and vulvar wall as well as petechiae on mucus membranes. On opening the uterus, there was presence of about 3-4 litres of blood tinged to light brown coloured purulent materials with creamy consistency (Sachan et al. 2019). The pyometric uterus collected during surgical removal revealed distension with presence of increased sero-sanguineous pus materials in the uterine lumen (Fig $2 \mathrm{~A}$ ), corrugations of the endometrium with thickened uterine wall and increased nodularity in the endometrial mucosa (Pulgarin et al. 2017). Flabby uterine horns with thick and corrugated endometrium containing profuse malodorous sero-sanguineous exudates were consequences of chronic inflammatory response in pyometra (Biswas et al. 2012). There was presence of persistent corpus luteum along with large ovarian cyst (Fig 2B) which might serve as an important source of progesterone thus complicating the disease pathology and pathogenesis (Agrawal et al. 2015). In some of the cases, sloughing of endometrial wall along with haemorrhages was evident. In majority of cases, copious purulent malodorous materials in uterine lumen along with scalding of vulva were observed during necropsy. Necrosis as well as hemorrhagic patches in uterus was associated with toxaemia (Demirel et al. 2018). All the internal organs were congested with petechial on serosae and mucosal surfaces. Kidney was congested with rough cortical surfaces. Haemorrhages, necrosis and ulcerations were clearly evidenced in urinary bladder mucosa along with thickened urinary bladder wall. There was presence of blood-tinged urine in the urinary bladder suggestive of urinary tract infection. Degenerative changes with haemorrhagic foci were noticed in liver. Lungs were congested. Dehydration, degenerative changes in liver and kidney along with cystitis as well as petechiae on various serosa and mucosal membranes were observed in the present research study which could be mainly attributed to septicaemia and multi-organ failure due to endotoxins released by bacteria (Demirel et al. 2018).

\section{Histopathology}

Representative tissue samples from the affected uterus were processed for routine histopathology. There were erosions and ulcerative lesions in the endometrial epithelial layers along with infiltrations of inflammatory cells. Mucosal epithelial necrosis, sub-mucosal glandular necrosis along with haemorrhages and infiltration of inflammatory cells were clearly evident. Diffuse haemorrhages were also observed in mucosal surfaces of endometrium along with cystic endometrial hyperplasia. Inflammatory infiltrates were predominantly polymorph nuclear cells (PMNC) comprising neutrophils and mononuclear like lymphocytes. Extravasated red blood cells (RBCs) leading to wide spread haemorrhages

Table 2: Mean $\pm S E$ of serum biochemical parameters in canine pyometra.

\begin{tabular}{|c|c|c|c|c|}
\hline Parameters & $\begin{array}{l}\text { Healthy control } \\
\qquad(n=10)\end{array}$ & $\begin{array}{l}\text { Pyometra cases } \\
(n=23)\end{array}$ & DF & P-value \\
\hline Total protein $(\mathrm{g} / \mathrm{dl})$ & $6.71 \pm 0.16^{a}$ & $8.11 \pm 0.16^{b}$ & 31 & $<0.0001$ \\
\hline Glucose (g/dl) & $55.77 \pm 0.13^{a}$ & $48.46 \pm 0.75^{b}$ & 31 & $<0.0001$ \\
\hline Albumin (g/dl) & $3.80 \pm 0.15^{a}$ & $2.87 \pm 0.01^{b}$ & 31 & $<0.0001$ \\
\hline AST (IU/L) & $54.10 \pm 2.40^{\mathrm{a}}$ & $75.00 \pm 0.89^{b}$ & 31 & $<0.0001$ \\
\hline ALT (IU/L) & $9.50 \pm 0.65^{a}$ & $18.04 \pm 0.40^{\mathrm{b}}$ & 31 & $<0.0001$ \\
\hline ALP (IU/L) & $77.40 \pm 1.88^{a}$ & $141.00 \pm 1.79^{b}$ & 31 & $<0.0001$ \\
\hline BUN (mg/dl) & $30.20 \pm 1.00^{a}$ & $57.69 \pm 0.73^{b}$ & 31 & $<0.0001$ \\
\hline
\end{tabular}

"Mean \pm SE with different superscripts differ significantly $(P<0.05)$.

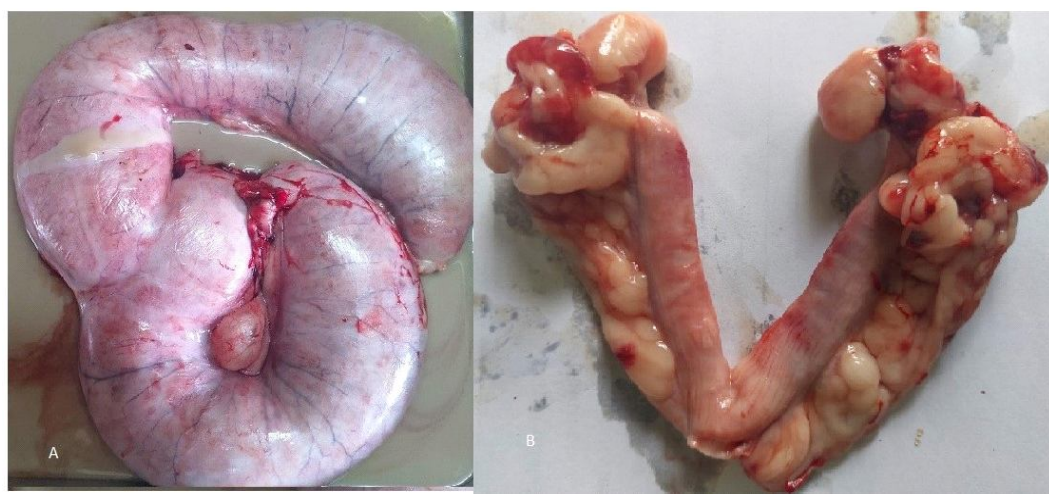

Fig 2: Gross lesions of uterus showing: (A) Distended uterus with presence of increased sero-sanguineous pus materials in the uterine lumen. $(B)$ presence of persistent corpus luteum along with large ovarian cyst. 


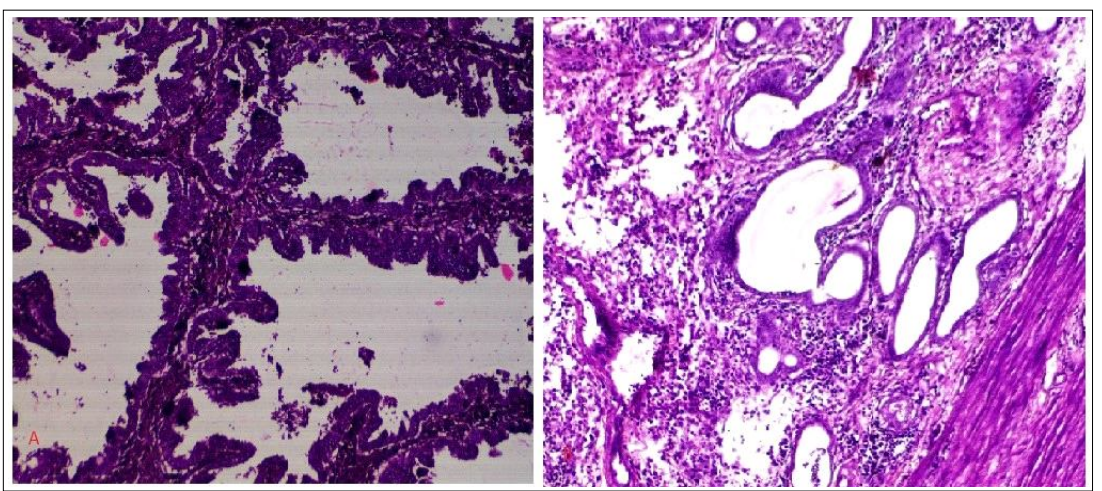

Fig 3: Microscopic lesions in uterus showing: (A) Hyperplastic growths of endometrial glands leading to aberrant arrangements of epithelial linings. (B) Cystic appearance of sub-mucosal gland along with presence of fluids in glandular lumen and marked infiltrations of neutrophils, macrophages and plasma cells.

were clearly observed as important microscopic lesions in most of the cases. Hyperplasic growths of endometrial glands leading to aberrant arrangement of epithelial linings (Fig 3A) were the typical appearance characteristics of cystic endometrial hyperplasia (CEH) in majority of pyometra cases. Besides, there were cystic degenerations, papillary hyperplasia and presence of small to large cysts in gland uteri. Leucocytosis along with swelling of endothelial cells was manifested in stratum vascularae of the uterus. Atrophy of uterine glands was evident in some cases of open cervix pyometra along with squamous metaplasia as well as fibrosis of the endometrium. Polypoid like growths with papillary projections in endometrium were much common findings during histopathology in pyometra. At instances, there was fibrosis in both endometrium and myometrium. Endometrial mucosal sloughing, necrosis of sub-mucosal glandular epithelial lining along with presence of mononuclear cells were characteristic findings in pyometra. Cystic appearance of sub-mucosal gland along with presence of fluids in glandular lumen and marked infiltrations of neutrophils, macrophages and plasma cells were observed as major microscopic lesion in pyometra (Fig 3B). Necrosis, haemorrhages, congestion along with inflammatory lesions was more dominant in endometrium rather than myometrium in open cervix pyometra. Major histopathological alterations in pyometric bitches were attributed to acute to chronic inflammatory response leading to intense haemorrhages, hyperaemia in tunica muscularis, oedema and congestion with fibroblastic proliferation in stromal connective tissues along with squamous metaplasia of endometrial epithelial cells. The present findings were in line with the observations of Coggan et al. (2008), Pulgarin et al. (2017) and Demirel et al. (2018). Predominant histopathological findings of uterus included cystic endometrial hyperplasia, fibroblastic proliferation around the endometrial glands along with infiltrations of polymorph as well as mononuclear cells (Balka et al. 2011).

\section{Microbiology of uterine contents}

The culture of the uterine exudates $(n=8)$ and Gram's staining concluded $E$. coli accounts highest $(67.5 \%)$ followed by Staphylococci $(22.5 \%)$ and Streptococci (10\%). A total of eight uterine exudates screened positive for bacterial infection were processed for antibiotic sensitivity test by Disc diffusion method by using nine different antibiotic discs. Present ABST study concluded about higher degree of sensitivity to ciprofloxacin, azithromycin, streptomycin and amoxycilin but showed resistant to penicillin $G$ and ampicillin which were in accordance with Robaj et al. 2018. Resistant to common antibiotics like Penicillin $\mathrm{G}$ and ampicillin might be associated with uncontrolled and aberrant use of such cheap and easily affordable antibiotics by the pet practitioners.

\section{CONCLUSION}

Early diagnosis through ultrasonography along with altered haemato-biochemical parameters may be routinely conducted to screen the dogs for pyometra to limit the mortality and un-warranted expenditure on treatment. The present study focussed on the various epidemiological determinants, pathomorphological alterations along with changes observed through diagnostic imaging that might fill the knowledge gap among the field veterinarians to assess the clinical severity to module the therapeutic modus operandi to cure the affected bitches.

\section{ACKNOWLEDGEMENT}

Authors are very much thankful to the Dean, College of Veterinary Science and Animal Husbandry, Odisha University of Agriculture and Technology, Bhubaneswar for providing necessary support to complete this study. Field veterinarians and concerned pet owners are equally thankful for extending their hearty co-operation and support during the study.

\section{REFERENCES}

Agrawal, J.K., Saxena, A., Kumar, P. and Patel, A. (2015). A critical case of closed cervix pyometra in a bitch. International Journal of Livestock Research. 5(10): 79-82.

Antonov, A.L., Atanasov, A.S., Fasulkov, I.R., Georgiev, P.I., Yotov, S.A., Karadaev, M.P. and Vasilev, N.Y. (2015). Influence of some factors on the incidence of pyometra in the bitch. Bulgarian Journal of Veterinary Medicine. 18(4): 367-372. 
Balka, G., Szabo, L. and Jakab, C. (2011). First report of an endometrial adenocarcinoma in a dog. Acta Veterinaria Hungarica. 59: 225-236.

Biswas, D., Das, S., Das, B.C. and Saifuddin, A.K.M. (2012). Pyometra in a German Shepherd Dog; A Clinical Case Report. Asian Journal of Animal and Veterinary Advances. 7(5): 446-451.

Coggan, J.A., Melville, P.A., Oliveira, C.M., Faustino, M., Moreno, A.M. and Benites, N.R. (2008). Microbiological and histopathological aspects of canine pyometra. Brazilian Journal of Microbiology. 39: 477-483.

Demirel, M.A., Atalay, V.S., Vural, R., Kutsal, O., Günen, Z. and Küplülü, Ş. (2018). Clinical, bacteriological and histopa thological aspects of endotoxic pyometra in bitches. Kafkas Universitesi Veteriner Fakultesi Dergisi. 24 (5): 663-671.

Ergene, O., Celebi, B. and Kucukaslan, I. (2019). Seroprevalence of canine Brucellosis and Toxoplasmosis in female and male dogs and relationship to various factors as parity, abortion and pyometra. Indian Journal of Animal Research. 53: 954-958.

Gasser, B., Uscategui, R.A.R., Maronezi, M.C., Pavan, L., Simoes, A.P.R., Martinato, F., Silva, P., Crivellenti, L.Z. and Feliciano, M.A.R. (2020). Clinical and ultrasound variables for early diagnosis of septic acute kidney injury in bitches with pyometra. Scientific Reports. 10: 8994.

Hagman, R. (2018). Pyometra in Small Animals. Veterinary Clinics of North America. Small Animal Practice. 48: 639-661.

Jitpean, S., Ström-Holst, B., Emanuelson, U., Höglund, O.V., Pettersson, A., Alneryd-Bull, C. and Hagman, R. (2014). Outcome of pyometra in female dogs and predictors of peritonitis and prolonged postoperative hospitalization in surgically treated cases. BMC Veterinary Research. 10: 6 .

Kumar, A. and Saxena, A. (2018). Canine pyometra: current perspectives on causes and management- $A$ Review. The Indian Journal of Veterinary Sciences and Biotechnology. 14(1): 52-56.

Mojzisova, J., Valocky, I. and Maracek, I. (2000). Monitoring of selected immunological parameters in bitches with glandular cystic hyperplasia pyometra complex before and after ovario-hysterectomy. Polish Journal of Veterinary Sciences. 3: 23-27.

Pulgarin, D.M., Dominguez, M.S.G., Taborda, D.A., Mendoza, N. and Estrada, J.G.M. (2017). Histopathologic findings in uteri and ovaries collected from clinically healthy dogs at elective ovariohysterectomy: A cross-sectional study. The Journal of Veterinary Science. 18(3): 407-414.

Rautela, R. and Katiyar, R. (2019). Review on canine pyometra, oxidative stress and current trends in diagnostics. Asian Pacific Journal of Reproduction. 8: 45-55.

Robaj A, Sylejmani D and Hamidi A. (2018). Occurrence and antimicrobial susceptibility of bacterial agents of canine pyometra. Indian Journal of Animal Research. 52(3): 397-400.

Sachan, V., Agrawal, J.K., Kumar, A. and Saxena, A. (2019). Diagnosis and treatment of canine Pyometra: A Review. Journal of Entomology and Zoology Studies. 7(2): 939-942.

Shah, S.A., Sood, N.K., Wani, B.M., Rather, M.A., Beigh, A.B. and Amin, U. (2017). Haemato-biochemical studies in canine pyometra. Journal of Pharmacognosy and Phytochemistry. 6(4): 14-17.

Simon, S., Ganesh, M.R., Arunprasad, A. and Suresh, R. (2011). Incidence of pyometra in bitches - A survey of 278 cases. Tamil Nadu Journal of Veterinary and Animal Sciences. 7(5): 252-253.

Sridevi, P., Kulasekar, K., Arunmozhi, N., Rangasamy, S., Joseph, C. and Rajasundaram, R.C. (2011). Ultrasonographic Diagnosis of Cystic Endometrial Hyperplasia-pyometra in Bitches. The Indian Journal of Animal Reproduction. 32(2): $52-53$.

Sugiura, K., Nishikawa, M., Ishiguro, K., Tajima, T., Inaba, M. and Torrii, R. (2004). Effect of ovarian hormones on periodical changes in immune resistance associated with estrous cycle in the beagle bitch. Immunobiology. (209): 619-627.

Verstegen, J., Dhaliwal, G. and Onclin, K.V. (2008). Mucometra, cystic endometrial hyperplasia and pyometra in the bitch: Advances in treatment and assessment of future reproductive success. Theriogenology. 70: 364-374.

Wheaton, L.G., Johnson, A.L., Parker, A.J. and Kneller, S.K. (1987). Results and complications of surgical treatment of pyometra: A review of 80 cases. Journal of American Animal Hospital Association. 25: 563-568. 